American Journal of Infectious Diseases 1 (1): 50-54, 2005

ISSN 1553-6203

(C) 2005 Science Publications

\title{
Factors Associated with Syringe Sharing Among Users of a Medically Supervised Safer Injecting Facility
}

\author{
${ }^{1,2}$ Evan Wood, ${ }^{1,2}$ Mark W. Tyndall, ${ }^{1}$ Jo-Anne Stoltz, ${ }^{1}$ Will Small, ${ }^{1}$ Elisa Lloyd-Smith, ${ }^{1}$ Ruth Zhang, \\ ${ }^{1}$ Julio S.G. Montaner and ${ }^{1}$ Thomas Kerr \\ ${ }^{1}$ BC Centre for Excellence in HIV/AIDS, St. Paul's Hospital \\ ${ }^{2}$ Department of Infectious Diseases; Faculty of Medicine, University of British Columbia \\ Vancouver British Columbia, Canada
}

\begin{abstract}
Vancouver, Canada recently opened a medically supervised safer injecting facility (SIF) in an effort to reduce HIV and overdose risk and public injection drug use. We sought to examine factors associated with syringe sharing among SIF users. SIF users were randomly recruited into a prospective cohort of SIF users known as the Scientific Evaluation of Supervised Injecting (SEOSI) cohort. We examined the prevalence and correlates of used syringe borrowing among baseline HIV-negative participants and used syringe lending among baseline HIV-infected participants. Between 22 March 2004 and 22 October 2004, 479 baseline HIV-negative subjects (48 [10\%] syringe borrowing events) and 103 baseline HIV-infected participants (17 [16.5\%] syringe lending events) were recruited into the cohort. For baseline HIV negative participants, syringe borrowing was positively associated with public drug use $(\mathrm{p}<0.001)$ and requiring help injecting $(\mathrm{p}=0.001)$, whereas exclusive SIF use was inversely associated with syringe sharing $(\mathrm{p}=0.019)$. For baseline HIV-infected participants, syringe lending was positively associated with daily cocaine injection $(\mathrm{p}=0.022)$ and shooting gallery use $(\mathrm{p}=0.007)$. Although ongoing injection-related HIV risk behavior was reported among some SIF users, rates of syringe sharing were substantially lower than the rate observed previously in this community and it is noteworthy that exclusive SIF use was associated with reduced syringe sharing.
\end{abstract}

Key words: SEOSI, safer injecting facility, reduced syringe sharing, risk factors for syringe sharing

\section{INTRODUCTION}

Injection drug use continues to be a primary driver of the HIV epidemic in many areas around the globe ${ }^{[1]}$. While there is strong evidence to suggest that substantial sexual transmission of HIV occurs ${ }^{[2,3]}$, it has been demonstrated that syringe sharing is a primary driver of HIV transmission within this population ${ }^{[4,5]}$. Accordingly, efforts to reduce syringe sharing among injection drug users (IDUs) have received significant attention and efforts to increase the provision of sterile syringes through needle exchange programs and other means have been adopted ${ }^{[6,7]}$. More recently, medically supervised safer injecting facilities (SIF) have been implemented in an effort to reduce public drug use, HIV risk behaviour and overdose deaths ${ }^{[8,9]}$.

We have recently examined factors associated with syringe sharing among a community recruited sample of IDUs in a setting where a SIF has recently been opened $^{[10]}$. In this study, we demonstrated that SIF use was associated with reduced syringe sharing. However, this study only demonstrated that SIF use was associated with reduced syringe sharing and little is known about what leads to syringe sharing among users of SIF. The present study was therefore conducted to examine the prevalence and correlates of syringe sharing among users of North America's first government sanctioned SIF which opened in Vancouver, Canada on September 22, 2003.

\section{MATERIALS AND METHODS}

The Vancouver SIF, known as Insite, is centrally located in Vancouver's Downtown Eastside, which is the most impoverished urban neighborhood in Canada and home to well documented infectious disease epidemics among the estimated 5,000 IDUs that reside there ${ }^{[11]}$. The SIF is being evaluated through the Scientific Evaluation of Supervised Injecting (SEOSI) cohort, which has been described in detail previously $^{[12]}$. Briefly, the SEOSI cohort is based on a representative sample of Insite users. This sample was derived through random recruitment of SIF users who provide informed consent to enroll into the study. Random recruitment involves using random number generation to select blocks of time during the hours that Insite is open (between 10:00am and 4:00am). During these times, users of the SIF are invited to enroll in the SEOSI study and a nominal financial incentive $(\$ 20$ $\mathrm{CDN}$ ) is offered to those who attend the research site,

Corresponding Author: $\quad$ Evan Wood, Ph.D. University of British Columbia/St. Paul's Hospital, 667-1081 Burrard Street, Vancouver, B.C. V6Z 1Y6, Canada, Tel: (604) 806-9116, Fax: (604) 806-9044 
located one block away from Insite. Among individuals who wish to enroll in the SIF evaluation and provide informed consent, a venous blood sample is drawn and an interviewer-administered questionnaire is conducted. The SEOSI cohort has been ethically approved by the University of British Columbia/Providence Healthcare Research Ethics Board.

The primary endpoints in the present study were borrowing a used syringe in the last six months among HIV-negative participants and lending a used syringe in the last six months among HIV-infected participants. Since we were primarily concerned with syringe sharing in the community that had occurred after the SIF was available and since the measure of syringe sharing was in reference to the prior six months, we only considered participants who were recruited during the period beginning six months after the SIF had opened (March 22 $\left.{ }^{\text {nd }}, 2004\right)$ and at the end of the first follow-up period (October 22, 2004).

Variables considered in these analyses included: age, gender, difficulty accessing sterile syringes (yes vs no), daily cocaine injection (yes vs no), daily heroin injection (yes vs no), public drug use (yes vs no), shooting gallery use (yes vs no), requiring help with injections (yes vs no), binge drug use (yes vs no), current Methadone Maintenance Therapy (MMT) use (yes vs no), sex-trade involvement (yes vs no), having been in jail overnight or longer (yes vs no), sexual abuse history (yes vs no) and exclusive use of the SIF for injection drug use during the month prior to the interview (yes vs no). Unless otherwise noted, all behavioral variables were in regard to the six months prior to the interview, with the exception of sexual abuse history which referred to ever in the past. Definitions of drug use behaviors were identical to previous reports ${ }^{[13,14]}$.

Variables potentially associated with syringe lending and borrowing were examined in bivariate analyses using Pearson's Chi-square test and the Wilcoxon rank sum test. All statistical analyses were performed using SPSS 12.0. All p-values are two sided with a significance level of $\mathrm{p}<0.05$.

Table 1: Bivariate analyses of factors associated with syringe borrowing among HIV-negative participants

\begin{tabular}{|c|c|c|c|c|}
\hline Characteristic & Borrowed n (\%) & No Borrow n (\%) & Odds Ratio (95\% CI) & $\mathrm{p}$ value \\
\hline \multicolumn{5}{|l|}{ Gender } \\
\hline Male & $32(66.7)$ & 310 (71.9) & $0.78(0.41-1.47)$ & 0.444 \\
\hline Female & $16(33.3)$ & $121(28.1)$ & & \\
\hline \multicolumn{5}{|c|}{ Hard Getting Syringes } \\
\hline Yes & $9(18.8)$ & $58(13.5)$ & $1.48(0.68-3.22)$ & 0.316 \\
\hline No & $39(81.2)$ & $373(86.5)$ & & \\
\hline \multicolumn{5}{|c|}{ Daily Cocaine Injection } \\
\hline Yes & $10(20.8)$ & $103(23.9)$ & $0.84(0.40-1.74)$ & 0.635 \\
\hline No & $38(79.2)$ & $328(76.1)$ & & \\
\hline \multicolumn{5}{|c|}{ Daily Heroin Injection } \\
\hline Yes & $26(54.2)$ & $211(49.0)$ & $1.23(0.68-2.24)$ & 0.493 \\
\hline No & $22(45.8)$ & $220(51.0)$ & & \\
\hline \multicolumn{5}{|c|}{ Public Drug Use } \\
\hline Yes & $45(93.8)$ & $293(68.0)$ & $7.07(2.16-23.13)$ & $<0.001$ \\
\hline No & $3(6.2)$ & $138(32.0)$ & & \\
\hline \multicolumn{5}{|c|}{ Shooting Gallery Use } \\
\hline Yes & $7(14.6)$ & $38(8.8)$ & $1.77(0.74-4.21)$ & 0.194 \\
\hline No & $41(85.4)$ & $393(91.2)$ & & \\
\hline \multicolumn{5}{|c|}{ Require Help injecting } \\
\hline Yes & $26(54.2)$ & $135(31.3)$ & $2.59(1.42-4.74)$ & 0.001 \\
\hline No & $22(45.8)$ & 296 (68.7) & & \\
\hline \multicolumn{5}{|c|}{ Binge Drug Use } \\
\hline Yes & $28(58.3)$ & $255(59.2)$ & $0.97(0.53-1.77)$ & 0.912 \\
\hline No & $20(41.7)$ & $176(40.8)$ & & \\
\hline \multicolumn{5}{|l|}{ On Methadone } \\
\hline Yes & $11(22.9)$ & $90(20.9)$ & $1.13(0.55-2.30)$ & 0.743 \\
\hline No & $37(77.1)$ & $341(79.1)$ & & \\
\hline \multicolumn{5}{|c|}{ Sex-trade Involvement } \\
\hline Yes & $12(25.0)$ & 89 (20.6) & $1.28(0.64-2.56)$ & 0.483 \\
\hline No & $36(75.0)$ & $342(79.4)$ & & \\
\hline \multicolumn{5}{|c|}{ Recently Incarcerated } \\
\hline Yes & $3(6.3)$ & $16(3.7)$ & $1.73(0.49-6.16)$ & 0.424 \\
\hline No & $45(93.8)$ & $415(96.3)$ & & \\
\hline \multicolumn{5}{|c|}{ Sex abuse History } \\
\hline Yes & $19(39.6)$ & $125(29.0)$ & $1.60(0.87-2.97)$ & 0.129 \\
\hline No & $29(60.4)$ & $306(71.0)$ & & \\
\hline \multicolumn{5}{|c|}{ Exclusive SIF Use } \\
\hline Yes & $0(0.0)$ & $42(9.7)$ & $0.14(0.00-0.78)$ & 0.019 \\
\hline No & $48(100.0)$ & $389(90.3)$ & & \\
\hline
\end{tabular}




\section{RESULTS AND DISCUSSION}

Between 22 March 2004 and 22 October 2004, 594 individuals were recruited into the SEOSI cohort among whom $479(80.6 \%)$ were baseline HIV-negative and $103(17.3 \%)$ were baseline HIV-infected. Twelve $(0.02 \%)$ individuals were excluded because HIV serology was unavailable at the time of this analysis. There were no statistical differences in age, gender, ethnic background, daily cocaine use and daily heroin use between the 303 individuals who were recruited during the first six months after the SIF opened and the 582 individuals who eligible for the present study (all p>0.05). Overall, among the 479 baseline HIV-negative individuals, 48 (10\%) reported borrowing a used syringe in the prior six months. As shown in Table 1, syringe borrowing among HIV-negative subjects was positively associated with public drug use (Odds Ratio [OR] 7.07, [95\% Confidence Interval [CI]: 2.16 - 23.13]; $\mathrm{p}<0.001)$ and requiring help injecting (OR 2.59, [95\% CI: 1.42 - 4.74]; $\mathrm{p}=0.001$ ). Conversely, syringe borrowing was inversely associated with performing all injections in the last month within the SIF (OR 0.14, [95\% CI: 0.00- 0.78]; $\mathrm{p}=0.019$ ).

Overall, among the 103 baseline HIV-positive individuals who were eligible for the present study, 17 $(16.5 \%)$ reported lending a used syringe in the prior six months. As shown in Table 2, syringe lending was associated with daily cocaine injection (OR 3.42, [95\% CI: $1.15-10.2] ; \mathrm{p}=0.022)$ and shooting gallery use (OR 6.16, [95\% CI: 1.75 - 21.70]; $\mathrm{p}=0.007)$. Both public drug use (OR 6.19, [95\% CI: $0.78-49.30]$; $\mathrm{p}=0.065$ ) and binge drug use (OR 3.36, [95\% CI: 0.90 - 12.56]; $\mathrm{p}=0.060$ ) were marginally associated with syringe lending.

The present study indicates that a minority of SIF users continue to share syringes outside of the SIF. Factors positively associated with used syringe borrowing included public injection drug use and requiring help injecting, whereas exclusive SIF use in the month prior to the baseline interview was associated with lower syringe sharing. Among baseline HIVinfected participants, syringe lending was associated with cocaine injection and shooting gallery use.

Table 2: Bivariate analyses of factors associated with syringe lending among HIV-positive participants

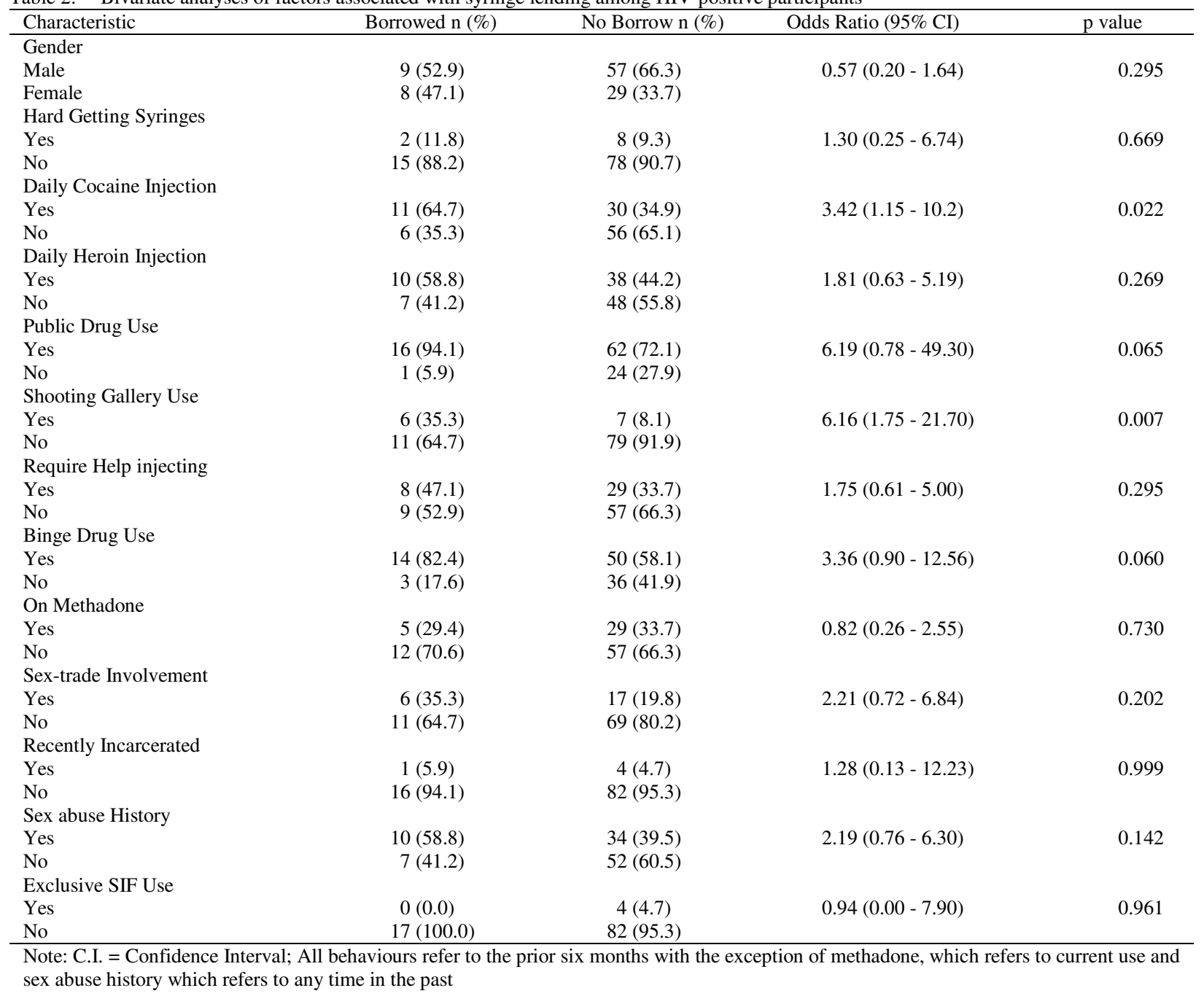


Among IDUs in this setting, we have previously reported semi-annual syringe lending and borrowing rates that are significantly higher than those observed among the SIF users considered in the present study ${ }^{[5}$, ${ }^{15]}$. Lower rates of syringe sharing among SIF users is consistent with a recent report ${ }^{[10]}$ and is likely due to the reduced risks associated with injecting in a hygienic environment where sterile syringes are provided. The fact that no instances of syringe lending or borrowing were observed among individuals who reported performing all injections within the SIF is encouraging, although it is noteworthy that the SIF can only accommodate 12 injectors at any given time and the capacity is such that the SIF can only service a fraction of the injections occurring in the community. With regard to the risk factors for syringe lending and borrowing identified in the present study, the fact that requiring help with injections was associated with syringe borrowing is not surprising given that it has been shown to be among the strongest determinants of syringe sharing and HIV-infection in this community in several earlier analyses ${ }^{[10,13,14]}$. This finding also has immediate relevance of SIF operation since these participants may benefit from safer injecting education and since assisted injection is not presently allowed within the $\operatorname{SIF}^{[12,16]}$. It is also interesting that public drug use and shooting gallery use were associated with syringe sharing among SIF users, given that homeless and public drug users may be more likely to use the $\mathrm{SIF}^{[17]}$. This association will have to be explored further in future studies, since reducing wait times at the SIF, extending operating hours and performing outreach into shooting galleries may all be helpful in addressing this concern.

The present study has limitations. First, previous studies have demonstrated that socially stigmatized behaviours, such as syringe sharing, may be underreported by IDUs ${ }^{[18]}$. While it is likely that rates of syringe sharing were under-estimated in the present study, we know of no reason why drug use characteristics or other risk factors would be differentially reported by IDUs that exhibited the risk factors we identified, such as public drug use or requiring help injecting. Finally, it is arguable that ethnographic inquiry and qualitative analyses may have the potential to help determine why specific risk factors, such as public injection drug use and shooting gallery use, were associated with elevated rates of syringe sharing in this environment.

\section{CONCLUSION}

In conclusion, we found that syringe sharing remains prevalent among a minority of SIF users, although rates of syringe sharing among this population are substantially lower than the rate observed previously in this community and it is noteworthy that exclusive SIF use was associated with reduced syringe sharing. This finding is particularly significant because it confirms earlier findings through an independent data source ${ }^{[10]}$. Further study is required to examine whether the risk factors for syringe sharing identified in the present study will be amenable to further reduction through modification of potential barriers to SIF use, such as modifying SIF operating hours and regulations that prohibit assisted injection within the SIF.

\section{ACKNOWLEDGMENTS}

The authors wish to thank the staff of the InSite SIF and Vancouver Coastal Health (Chris Buchner, Heather Hay, Dr. David Marsh). We also thank Bonnie Devlin, Evelyn King, Aaron Eddie, Peter Vann, Dave Isham, Daniel Kane, Steve Gaspar, Carl Bognar, Megan Oleson and Suzy Coulter for their research and administrative assistance. The SIF evaluation has been made possible through a financial contribution from Health Canada, though the views expressed herein do not represent the official policies of Health Canada.

\section{REFERENCES}

1. Kerr, T., A. Wodak, R. Elliot, J.S. Montaner and E. Wood, 2004. Opiod substitution therapy and HIV/AIDS treatment and prevention. Lancet, 364: 1918-1919.

2. Kral, A.H., R.N. Bluthenthal, J. Lorvick, L. Gee, P. Bacchetti and B.R. Edlin, 2001. Sexual transmission of HIV-1 among injection drug users in San Francisco, USA: risk-factor analysis. Lancet, 357: 1397-401.

3. Strathdee, S.A., N. Galai, M. Safaeian, D.D. Celentano, D. Vlahov and J. Lisette et al., 2001. Sex differences in risk factors for HIV seroconversion amon injection drug users: A ten year perspective. Arch. Internal Med., 161: 1281-1288.

4. Tyndall, M.W., S. Currie, P. Spittal, K. Li, E. Wood and M.V. O'Shaughnessy et al., 2003. Intensive injection cocaine use as the primary risk factor in the Vancouver HIV-1 epidemic. AIDS, 17: 887-93.

5. Wood, E., M.W. Tyndall, P.M. Spittal, K. Li, R.S. Hogg and J.S. Montaner et al., 2002. Factors associated with persistent high-risk syringe sharing in the presence of an established needle exchange programme. AIDS, 16: 941-3.

6. Des Jarlais, D.C., M. Marmor, D. Paone, S. Titus, Q. Shi and T. Perlis et al., 1996. HIV incidence among injecting drug users in New York City syringe-exchange programmes. Lancet, 348: 987-91. 
7. Wood, E., M.W. Tyndall, P. Spittal, K. Li, R.S.H and M. O'Shaughnessy et al., 2002. Needle exchange and difficulty with needle access during an ongoing HIV epidemic. Intl. J Drug Policy, 13: 95-102.

8. Online: Final report of the evaluation of the Sydney medically supervised injecting centre. Available: http://www.sydneymsic.com/.

9. Wood, E., T. Kerr, J.S. Montaner, S.A. Strathdee, A. Wodak and C.A. Hankins et al., 2004. Rationale for evaluating North America's first medically supervised safer injecting facility. Lancet Infect. Dis., 4: 301-6.

10. Kerr, T., M. Tyndall, K. Li, J.S. Montaner and E. Wood, 2005. Safer injection facility use and syringe sharing in injection drug users. Lancet, (in press).

11. Kerr, T., E. Wood, D. Small, A. Palepu and M. Tyndall, 2003. Potential use of safer injecting facilities among injection drug users in Vancouver's downtown eastside. CMAJ, 169: 759-63.

12. Wood, E., T. Kerr, C. Buchner, D.C. Marsh, J.S. Montaner and M. Tyndall, 2004. methodology for evaluating insite: Canada's first medically supervised safer injection facility for injection drug users. Harm Reduction J., 1: 9.

13. O'Connell, J., T. Kerr, K. Li, M. Tyndal, R.S. Hogg and M.T. Schechter et al., 2004. Requiring help injecting independently predicts incident HIV infection among injection drug users. JAIDS, (In press).
14. Wood, E., P.M. Spittal, T. Kerr, W. Small, M.W. Tyndall and M.V. O'Shaughnessy et al., 2003. Requiring help injecting as a risk factor for HIV infection in the Vancouver epidemic: Implications for HIV prevention. Can. J. Public Health, 94: 3559.

15. Wood, E., T. Kerr, P.M. Spittal, K. Li, W. Small and M.W. Tyndall et al., 2003. The potential public health and community impacts of safer injecting facilities: Evidence from a cohort of injection drug users. J. Acquir. Immune. Defic. Syndr., 32: 2-8.

16. Kral, A.H., R.N. Bluthenthal, E.A. Erringer, J. Lorvick and B.R. Edlin, 1999. Risk factors among IDUs who give injections to or receive injections from other drug users. Addiction, 94: 675-83.

17. Wood, E., T. Kerr, W. Small, K. Li, D. Marsh and J.S. Montaner et al., 2004. Changes in public order after the opening of a medically supervised safer injecting facility for illicit injection drug users. CMAJ, 171: 731-4.

18. Des Jarlais, D.C., D. Paone, J. Milliken, C.F. Turner, H. Miller and J. Gribble et al., 1999. Audio-computer interviewing to measure risk behaviour for HIV among injecting drug users: A quasi-randomised trial. Lancet, 353: 1657-61. 